\title{
A CULTURA DA CIDADE E OS SEUS ESPAÇOS INTERMEDIÁRIOS: OS BARES E OS RESTAURANTES
}

THE CULTURE OF THE CITY AND ITS INTERMEDIATE SPACES:

BARS AND RESTAURANTS

\author{
ANA SÍLVIA ROCHA IPIRANGA \\ Doutora em Psicologia do Trabalho e da Organização pelo Programa de \\ Pós-Graduação da Università Degli Studi di Bologna, Itália. \\ Professora adjunta do Curso de Mestrado Acadêmico em Administração da \\ Universidade Estadual do Ceará (UECE). \\ Avenida Abolição, 2.480/1.004, Meireles - Fortaleza - CE - Brasil - CEP 60165-080 \\ E-mail: ana.silvia@pq.cnpq.br
}




\section{RESUMO}

A conformação de uma cidade e a organização de seus espaços formam uma base material por meio da qual é possível fazer uma reflexão sobre a gama de sensações e práticas sociais. A cidade, como espaço de interação e hibridismo, constrói e reconstrói no tempo identidades, produz e reflete significados, deslocando a atenção para esses processos sociais. Pressupõe-se que compreender o espaço urbano por meio da consideração da sua cultura e dos seus espaços intermediários - ruas, bairros e equipamentos como os bares e restaurantes - é uma forma de buscar meios de melhor geri-la. Este estudo tem como objetivo descrever os significados culturais atribuídos aos espaços intermediários, envolvendo a emergência de bares e restaurantes em três bairros contíguos de Fortaleza, discutindo os reflexos em termos de desenvolvimento socioterritorial da cidade. Para tanto, foi utilizado como enfoque metodológico uma pesquisa etnográfica, combinando variadas técnicas de coleta. $\mathrm{Na}$ análise das informações coletadas, utilizou-se a técnica da análise temática que se insere no conjunto das técnicas da análise de conteúdo. Evidenciaram-se tempos simultâneos e espaços diferenciados, nos quais "lugares" e "não lugares" coexistem significando os "entrelugares" e caracterizando a emergência de espaços intermediários no contexto de uma cidade dividida em duas, rica em simbolismos e interação, fragmentada e solitária, incapaz de compartilhar os códigos culturais, o que sugere desafios à sua gestão.

\section{PALAVRAS-CHAVE}

66 Cultura; Cidade; Desenvolvimento socioterritorial; Bares e restaurantes; Espaçotempo.

\section{ABSTRACT}

The conformation of a city and the organization of its spaces form a material base starting from which it is possible to think a possible range of sensations and social 
practices. The city, while interaction and hybridity space, builds and reconstructs in time identities, it produces and reflects meanings, moving the attention to those social processes. It is presupposed that to understand the urban space through the consideration of its culture and of its intermediate spaces - streets, neighborhoods and equipments such as bars and restaurants - it is a way of looking for best means to manage it. This study has as objective to describe the cultural meanings attributed to the intermediate spaces, involving the emerging of bars and restaurants in three contiguous neighborhoods of Fortaleza, discussing the reflexes in terms of socialterritorial development of the city. For such it was used, as methodological focus, an ethnographic research, combining varied collection techniques. The Thematic Analysis technique, which belongs to the Analysis of Content techniques group, was applied in the analysis of the collected information. Simultaneous times and differentiated spaces were evidenced, in which "places" and "non places" coexist meaning the "between places" and characterizing the emerging of intermediate spaces in the context of a city divided in two, rich in symbolisms and interaction, fragmented and solitary, unable to share the cultural codes suggesting challenges to its administration.

\section{KEYWORDS}

Culture; City; Social-territorial development; Bars and restaurants; Spacetime.

\section{INTRODUÇÃO}

No decorrer da história e na fundamentação do pensamento, duas importantes dimensões surgem, implícita ou explicitamente, como pano de fundo das compreensões do mundo no que tange à forma com base na qual interpretamos o que nos envolve e vivemos: a apreciação do espaço e do tempo.

As discussões sobre o tempo se conectam com a necessidade de se investigar a memória como um jogo em permanente construção, dirigindo a atenção para o espaço em que vivemos e a que sempre temos acesso como lugar de experiências, significados e simbolismos. Para Halbwachs (2006), não há grupo social nem tipo de atividade que não tenha alguma relação com o "lugar" como parte do espaço. Buscar a memória de uma cidade seria, portanto, observá-la, percebê-la e interpretá-la por meio dos seus lugares, da conservação e da invenção (LEITÃO, 200I).

Essa construção concreta e simbólica do espaço se relaciona aos conceitos, segundo Augé (2004), de "lugar antropológico" ao criar um "social orgânico" e 
de "não lugares" que dizem respeito aos seus fins, criando uma "tensão solitária". Os lugares e não lugares coexistem, misturam-se e caracterizam um mesmo espaço, onde um e outro jamais se realizam totalmente (AUGÉ, 2004).

Para fins deste estudo, considera-se ainda a perspectiva intersticial de Bhabha (I998), na qual os espaços liminares, os "entrelugares" de passagem, situados no meio das designações das identidades, se transformam no processo de interação simbólica, possibilitando os hibridismos culturais ao acolher as diferenças.

A cultura da cidade, como espaço de enraizamento, memórias, interação, fronteiras e hibridismo, constrói no tempo identidades, produz e reflete identificações, símbolos, signos e significados. Para Magnani (I99I), a metrópole contemporânea, apesar de sua diversidade e de seus problemas, comporta diferentes formas, fronteiras, interstícios, espaços liminares e singulares, por meio dos quais seus habitantes estabelecem vínculos entre si e com a cidade. Magnani (I99I) sublinha que algumas dessas formas podem ser analisadas em sua relação com o próprio espaço no qual ocorrem as "experiências da rua".

Segundo Magnani (I99I), as "experiências de rua" acontecem nos "espaços intermediários" entre o privado (a casa) e o público (a rua) (cf. DAMATTA, I99I), entre os quais se desenvolve uma "sociabilidade básica", mais ampla que a fundada nos laços familiares, porém mais densa, significativa e estável que as relações formais e individualizadas impostas pela sociedade (MAGNANI, I984, p. I38).

Nesse contexto, a cidade, suas ruas, seus bairros e equipamentos são espaços e suportes concretos de sociabilidade e experiências, formando uma base material com a qual é possível pensar, avaliar e realizar uma possível gama de sensações e práticas sociais compartilhadas.

Com base no pressuposto de que compreender e desvelar os espaços urbanos, sobretudo os espaços intermediários emersos na cidade e os significados que podem ser atribuídos a estes e à sua cultura, é uma forma de buscar meios de melhor geri-los, a presente pesquisa tem como objetivo: descrever os significados culturais atribuídos aos espaços intermediários, envolvendo a emergência de bares e restaurantes em três bairros contíguos - Varjota, Meireles, Aldeota - de Fortaleza, e discuitir os reflexos da sociabilidade produtiva e de lazer em termos de desenvolvimento socioterritorial da cidade.

A metodologia baseou-se na abordagem qualitativa, segundo o enfoque etnográfico, com a utilização de um conjunto de técnicas, como: a "etnografia de rua" (ECKERT; ROCHA, 2003), fundamentada na antropologia urbana (VELHO, I999) e complementada pelas técnicas da observação participante e da compilação de notas no "diário de campo" (MALINOWSKI, I975). Utilizaram-se ainda a entrevista temática e não estruturada realizada com os proprietários dos bares e restaurantes, e a pesquisa documental na Biblioteca Pública de Fortaleza, a fim 
de levantar dados históricos sobre o início da ocupação e formação residencial e comercial dos bairros envolvidos (PITT, I972 apud CAVEDON, 2003). Na análise das informações coletadas, foi utilizada a técnica da análise temática que se insere no conjunto das técnicas da análise de conteúdo (BARDIN, 2004).

Além desta introdução, o trabalho está estruturado da seguinte forma: a seguir, consideram-se as discussões da cultura da cidade, articulando as ideias de tempo e memória, de espaço e da emergência dos espaços intermediários no contexto da cidade. Na terceira seção, colocam-se em debate a cidade, a gestão e o desenvolvimento socioterritorial. Após se delineia a metodologia de suporte à investigação, seguida da contextualização e análise do estudo e das considerações finais.

\section{TEMPO, MEMÓRIA, ESPAÇO E A
CULTURA DA CIDADE}

No decorrer do tempo da civilização, modos distintos de formação social incorporaram um conjunto particular de práticas e apreciações diversas do tempo e do espaço para garantir a produção e reprodução da vida social. Como um esforço de reconstrução das subjetividades e reconstituição das diversas representações da realidade, percebe-se que quanto mais as sociedades progridem técnica ou cientificamente, mais apresentam a necessidade de investigar a memória e interpretá-la por meio de objetos, monumentos, imagens e relatos (HARVEY, I992).

Na construção contemporânea dos espaços urbanos, o arquiteto, por ocasião da edificação de uma forma espacial, busca comunicar certos valores e significados estabilizados nos monumentos que incorporam e preservam um sentido de memória coletiva. Harvey (I992) evidencia ainda que a arquitetura não é apenas a domesticação do espaço, mas uma defesa contra a tirania do tempo. Colocando-se como uma linguagem de uma realidade intemporal, ligando o tempo e a eternidade como algo forte o bastante para "parar" o tempo, "o espaço é o tempo cristalizado", um conjunto inseparável de sistemas de objetos e de ação e projetos (CASTELLS, I999; SANTOS, 2006).

Para Halbwachs (2006), não há grupo social nem tipo de atividade que não tenha alguma relação com o "lugar" como parte do espaço. Santos (2006) enfatiza que o "lugar" é a base da vida em comum, reunindo referências pragmáticas com solicitações de ações condicionadas, sendo também "o teatro das paixões humanas”, responsável pelas mais diversas manifestações da espontaneidade e da criatividade. Dessa forma, complementa Halbwachs (2006), não há memória coletiva que não aconteça em um contexto espacial. Para que as 
categorias de lembranças reapareçam, devemos dirigir nossa atenção para o espaço que ocupamos e em que vivemos, por onde passamos muitas vezes e a que sempre temos acesso.

Buscar a memória de uma cidade seria, portanto, observá-la, percebê-la e interpretá-la por meio dos seus lugares, das suas falas e dos seus silêncios, das suas lembranças e dos seus esquecimentos, da conservação e da invenção. A memória não como um estoque, mas como um jogo em permanente reconstrução, que, para tanto, necessita de lugares, sentidos, ritos, gestos, sensações, enraizamento que a torne capaz de sobreviver ao esvaziamento e desconhecimento (LEITÃO, 200I).

DaMatta (I99I), ao abordar o espaço, propõe uma divisão entre dois espaços sociais fundamentais - o mundo da "casa" e o mundo da "rua" - que dividem a vida social brasileira. Para o autor, a "rua" é uma categoria sociológica que designa mais que simplesmente um espaço geográfico. Antes de tudo, é uma entidade moral, esfera de ação social, domínio cultural capaz de despertar emoções, reações e imagens esteticamente emolduradas e inspiradas, onde predominam a desconfiança e a insegurança. Essa percepção do espaço é o reflexo do isolamento e da individualização que, segundo DaMatta (I997), espelha o ponto crítico da identidade social brasileira.

Bourdieu (I996) fundamenta a noção de espaço pela ideia de diferença, como posições distintas e coexistentes, exteriores umas às outras, definidas umas em relação às outras por sua exterioridade mútua e por relações de proximidade, de vizinhança, de distanciamento, e ainda por relações de ordem, como acima, abaixo e entre. Santos (2006) explica que a questão da proximidade espacial vai além da ideia de distância, caracterizando-se em termos da contiguidade física entre as pessoas que vivem e se inter-relacionam numa mesma extensão, criando laços culturais e identidade.

Augé (2004) denomina de "lugar antropológico" essa construção concreta e simbólica do espaço, ao envolver as vicissitudes e contradições da vida social, como sentido para aqueles que o habitam e inteligibilidade para quem o observa. O autor classifica o "lugar" como "identitário", pois representa para as pessoas que o ocupam um conjunto de possibilidades, prescrições e proibições; "relacional", porque se trata de um espaço existencial e experiencial; e "histórico", pois se trata de "lugares de memória" com forte conteúdo simbólico, nos quais os indivíduos não fazem história, mas vivem na história, criando um "social orgânico".

Em oposição à ideia de "lugar antropológico" como espaços que não se caracterizam como identitários, nem como relacionais, nem como históricos, Augé (2004) propõe o conceito de "não lugares". Os "não lugares" são reconhecidos por duas realidades distintas, mas complementares. Trata-se de espaços constituídos 
em relação a determinados objetivos, como transporte, trânsito, comércio, lazer e espaços nos quais os indivíduos mantêm uma relação de uso, que dizem respeito a seus fins, criando uma "tensão solitária". O autor sublinha ainda que essas duas realidades - "lugar" e "não lugar" - coexistem e podem se misturar e caracterizar um mesmo espaço, no qual uma e outra jamais se realizam totalmente.

A ideia de lugar e a qualidade de diferente, similitude, proximidade e de separação que fundamenta a noção de espaço se articulam com a questão da identidade, como objeto, nas ciências humanas e sociais, de diversos modelos de ligação social (ARRUDA, I998). A discussão da identidade está inscrita no universo mais amplo da cultura. Para Geertz (1989), o conceito de cultura é essencialmente semiótico. Como o homem é um animal amarrado em teias de significados que ele mesmo teceu, assume-se, portanto, a cultura como sendo essas teias, e a sua análise, uma ciência interpretativa (GEERTZ, I989).

Nesse sentido e segundo Thompson (I990), a cultura passa a ser percebida como uma rede de estruturas significativas, um padrão de significados incorporado nas formas simbólicas - símbolos, ritos e rituais, sinais, trejeitos, lampejos, manifestações verbais, ações e objetos significativos de vários tipos - com os quais os indivíduos se comunicam e partilham suas experiências, concepções e crenças.

Os fenômenos culturais se inserem em contextos e processos sócio-históricos por meio dos quais estes são produzidos, transmitidos e recebidos. Tais contextos são espaçotemporais estruturados, moldando a maneira como as formas simbólicas são entendidas e valorizadas. Por sua vez, os indivíduos não absorvem passivamente formas simbólicas, mas lhes atribuem um sentido e produzem ativa e criativamente um significado, compreendendo-as e valorizando-as diferentemente em virtude da extensão em que eles são estimados, condenados, apreciados ou desprezados (THOMPSON, I990).

A cidade não é só o concreto. Parafraseando Barthes (1996), a cidade é um discurso, o qual é uma linguagem que revela os espaços que se pretendem eternos, sinalizados com palácios e igrejas, mercados e quartéis ou tudo aquilo capaz de emoldurar a vida social num sistema fixo de valores e poder. Contudo, nem sempre esses espaços são marcados pelo eterno. Há locais liminares, intersticiais, transitórios, margens sociais problemáticas, onde tudo o que está relacionado ao paradoxo ou à contradição desenha um espaço singular (DAMATTA, I997).

Certeau (1994), ao discutir uma base para a compreensão das culturas de rua populares e localizadas, sublinha que esses "espaços singulares", nos quais populações empobrecidas estão segredadas nos espaços adjacentes às cidades, são instâncias abertas à criatividade e ação do homem, dando uma forma aos espaços, unindo lugares, recriando a cidade por meio de atividades e movimentos diários na "invenção do cotidiano". 
Por sua vez, as cidades contemporâneas vivem tempos de mudanças, caracterizando-se pela mobilidade e pela circulação de pessoas, turistas, migrantes que mudam de lugares, assim como produtos, mercadorias, imagens e ideias que se desterritorializam e se virtualizam nos espaços (SANTOS, 2006).

O espaço fixa e enraíza em um mundo urbano fragmentado, que está sempre em fluxo, transitório, intercambiável em suas fronteiras e coexistente em suas diferenças, construindo e reconstruindo identidades pessoais e sociais, ao refletir a relação que o homem mantém com o ambiente e com os outros (CHANLAT, I993; HARVEY, I992).

Percebe-se ainda a cidade como uma grande teia organizacional, um todo constituído por inúmeras unidades organizativas multifacetadas, sendo ela mesma uma organização plena de significados (FISCHER et al., I997). Com histórias e identidades singulares, a cidade se mostra plural no que se refere às suas relações e manifestações, que podem favorecer a construção ou fortalecimento de identidades, fruto da experiência vivida no lugar (FISCHER et al., I997).

Ao considerar a cidade como complexa teia organizacional, propõe-se, segundo Hall (2005) e Carrieri, Paula e Davel (2008), a visão da identidade "em processo", "em andamento", decorrente da multiplicidade, fluida, autônoma, construída e reconstruída por meio da percepção e evocação de imagens, textos, impressões, julgamentos e situações que expressam algo sobre os indivíduos e sobre aqueles com quem esses indivíduos interagem (GHADIRI; DAVEL, 2006).

Ressalta-se ainda, para fins deste estudo, a perspectiva intersticial da minoria de Bhabha (I998, p. 2I) sobre "a negociação complexa e em andamento, que procura conferir autoridade aos hibridismos culturais que emergem em momentos de transformação histórica". O autor ressalta a necessidade de passar além das narrativas de subjetividades originárias e focalizar os momentos que são produzidos na articulação das diferenças culturais - os "entrelugares". Os "entrelugares" fornecem o terreno para a elaboração de estratégias de subjetivação - singular e coletiva - que dão início a novos signos de identidade e lugares inovadores de contestação e colaboração, no ato de definir a própria ideia de sociedade (BHABHA, I998, p. 20-2I).

Dessa forma, a conformação de uma cidade e a organização de seus espaços refletem uma base material por meio da qual é possível pensar, avaliar e realizar uma possível gama de sensações, significados e práticas sociais (CASTELLS, I999; HARVEY, I992). A cidade, como espaço de interação e hibridismo, constrói e reconstrói no tempo identidades, produz e reflete identificações, símbolos, rituais, signos e significados. Sendo, portanto, espaço de dualidades, de dessemelhanças e pluralidade: cidadania e marginalidade, sombras e luzes, ordem e desordem, solidariedade e conflito, lugar ocupado por organizações reais e virtuais, fluxo e transição. "Morada e lugar de encontro, a cidade é também o repo- 
sitório dos problemas da sociedade, cenário das crises, o lócus da impotência e do desencanto" (FISCHER et al., I997, p. 255). Descobre-se, portanto, um intricado sistema de complexidade, antes "organizada" do que "desorganizada", uma vitalidade e uma energia de interação social, e a atenção deve concentrar-se nesses processos de interação (HARVEY, I992).

\subsection{OS "ESPAÇOS INTERMEDIÁRIOS" DA CIDADE: OS BARES E OS RESTAURANTES}

Contrariamente ao que pensa o senso comum, a cidade não se impõe de forma homogênea e absoluta sobre seus moradores e visitantes, e, nesse sentido, considera-se a perspectiva da geografia humana ao salientar que o "lugar", impregnado de significados e simbolismos, refere-se a "lugares de experiências", envolvendo tanto a razão como a emoção (MESQUITA, I998).

Harvey (I992) citando Lefebvre (I974) afirma que a análise da vida cotidiana envolve concepções e apreciações na escala da "experiência social", incluindo a compreensão da apropriação dos lugares. Santos (2006) coaduna ao explicar que, no cotidiano compartilhado, a política se territorializa no confronto entre cooperação e conflito, organização e espontaneidade; no "lugar", a contiguidade física entre pessoas, organizações e instituições é criadora de comunhão, constituindo, por fim, a base da vida em comum.

Nesse âmbito, considera-se a observação de Magnani (I984) quando enfatiza que a cidade pode ser apreciada a partir do ponto de vista daqueles que nela vivem e daqueles que dela se apropriam. A apropriação do espaço examina a maneira como o espaço é ocupado por objetos (casas, ruas, fábricas, bares e restaurantes etc.), atividades (usos do solo, transporte, comunicação, organização territorial etc.), indivíduos, grupos e comunidades (HARVEY, I992). Magnani (i984) releva que essas formas de apropriação não são aleatórias nem o resultado de escolhas individuais, mas o resultado de rotinas e invenções cotidianas ditadas por injunções criativas e coletivas que regulam o trabalho, o lazer e a convivência, e que deixam seus signos no mapa da cidade.

Parafraseando Certeau (I994), "o andar com os pés na cidade" recorta "espaços de enunciação", caminhos entrecruzados que dão forma a novos espaços e unem lugares. Esse "andar" resulta num desenho bastante singular que se sobrepõe ao desenho oficial da cidade; "às vezes rompe com ele, outras vezes o segue, outras ainda não tem alternativa senão adequar-se” (MAGNANI, I993).

A cidade, suas ruas, seus bairros e equipamentos são espaços e suportes concretos de sociabilidade e experiências. Para Magnani (I99I), a metrópole contemporânea, apesar de sua diversidade e de seus problemas, comporta diferentes formas, fronteiras, espaços liminares e singulares, por meio dos quais seus habi- 
tantes estabelecem vínculos entre si e com a cidade. O autor sublinha que algumas dessas formas podem ser analisadas em sua relação com o próprio espaço no qual ocorrem as "experiências da rua" (MAGNANI, I99I).

As "experiências de rua" acontecem nos "espaços intermediários" entre o privado (a casa) e o público (a rua), entre os quais se desenvolve uma "sociabilidade básica”, mais ampla que a fundada nos laços familiares, porém mais densa, significativa e estável que as relações formais e individualizadas impostas pela sociedade (MAGNANI, I984, p. I38). Nesse contexto, Castells (1999) salienta que, "entre a casa e o mundo, há um lugar", cujas características marcam a vida de seus habitantes ao manterem uma interação ativa com seu ambiente físico diário.

Bhabha (I998) coaduna essa ideia quando sublinha que é na emergência dos interstícios, na sobreposição e no deslocamento das diferenças que as experiências intersubjetivas e coletivas, o interesse comunitário ou o valor cultural são negociados. Nessa perspectiva intersticial, os espaços liminares situados no meio das designações das identidades se transformam no processo de interação simbólica, pois "o movimento temporal e a passagem que ele propicia evita que as identidades se estabeleçam em polaridades primordiais, possibilitando hibridismos culturais ao acolher as diferenças" (BHABHA, I998, p. 2I-22).

No contexto das cidades, os diferentes equipamentos se caracterizam como definidores de fronteiras, intersticiais, liminares, delimitando o território da cidade e constituindo lugares de passagem, "espaços intermediários" de encontros e de sociabilidade produtiva e de lazer. Entretanto, não basta passar ou frequentar esses lugares, é preciso estar inserido numa peculiar rede de interações que combina diferentes laços de parentesco, vizinhança, profissionais, procedência, vínculos tecidos pela participação em diferentes atividades comunitárias, de trabalho e de lazer etc. Essa rede de relações instaura um código cultural dos lugares capaz de separar, ordenar, classificar esses fluxos nos espaços da cidade (MAGNANI, I993).

Magnani (I993) afirma, portanto, que, entre os dois padrões paradigmáticos de apropriação do espaço - o privado e o público -, existe uma gradação em que é possível distinguir diversos arranjos intermediários - calçadas, ladeiras, ruas, becos, praças, bairros, residências, escolas, museus, cinemas, bares e restaurantes -, espaços de sociabilidade, de escolhas reveladoras da dinâmica urbana, com base em uma lógica cultural e territorial, permitindo encontros imprevistos mas desejáveis e propiciando toda espécie de trocas:

É aí que se tece a trama do cotidiano; a vida do dia-a-dia, do trabalho, do desfrute do lazer, da troca de informações e de serviços, dos inevitáveis conflitos e da participação em atividades vicinais (MAGNANI, I993). 


\section{A CIDADE, A SUA GESTÃO E O DESENVOLVIMENTO SOCIOTERRITORIAL}

O tema "cidade" tem sido sistematicamente ignorado como objeto no campo de estudos organizacionais e eventualmente vem sendo abordado por meio de conceitos por vezes imprecisos e inclinados a uma redução do espaço à localização, espaço-físico ou abordado segundo a dimensão econômica (ALCADIPANI; ALMEIDA, 200I; CARRIERI; PEREIRA, 2003; MAC-ALLISTER, 2003a, 2003b).

Compreendendo que a cidade é uma organização social, com um conjunto de instituições, grupos e indivíduos que se situa no tempo e no espaço, possuidora de alta complexidade, processando coletiva e continuamente uma cultura, processo este que resulta em identidades sociais tanto relativas à totalidade da cidade quanto à gestão dessa totalidade, entende-se, pois, a importância de abordar a cidade como objeto de estudos na Administração (FISCHER, I996; FISCHER et al., I996).

A cidade como uma realidade plural e polifônica é, acima de tudo, o sentido que atribuímos a ela. Torna-se, pois, necessário abstrair a cidade de sua extrema materialidade e propor possibilidades de sentidos, significados e de gestão que possibilitem a convivência nas suas diferenças e culturas (BARBALHO, 2009).

A forma como a gestão de uma cidade faz uso dos espaços, seja a apropriação dos espaços físicos seja a apropriação simbólica, reflete fatores sobre a cultura de um determinado lugar, seus processos de identificação e suas relações de identidade, enraizamento, territorialização e até o desenraizamento, a desterritorialização (CARRIERI; PEREIRA, 2003; VASCONCELOS, 2003). A apropriação do espaço traduz a maneira como ele é ocupado, seja por objetos, equipamentos, atividades, indivíduos ou grupos. Contudo, é por meio da apropriação simbólica que as representações do mundo, do lugar são tecidas, transmitidas, assimiladas e integradas coletivamente (HARVEY, I992; BOURDIEU, I989, CARRIERI; PEREIRA, 2003).

Fortuna (200I) refere-se ao fato de que, apesar de as cidades contemporâneas estarem marcadas pelo contexto de desterritorialização dos fluxos, estas devem ser geridas para produzir um efeito de reterritorialização. Ainda segundo o autor, perante o atual processo de desterritorialização dos fluxos econômicos - financeiros, tecnológicos, culturais, informativos -, o desafio está na capacidade da gestão das diferentes cidades para procederem à sua reterritorialização, dependendo menos da dimensão das cidades e mais da intensidade, do grau e da espessura, para que sejam capazes de se dotar criativamente de segmentos desses fluxos. 
Tendo em vista uma perspectiva integrada do desenvolvimento, um dos grandes pilares das políticas públicas atuais está voltado para a regeneração urbano-geográfica e elevação da qualidade de vida das cidades e regiões, por meio do investimento em cultura como agente sinérgico, entrelaçando o tecido urbano com o social e os objetivos econômicos com os simbólicos (REIS, 2007). Nesse processo, a "cultura local" emerge como um fenômeno social difuso ao utilizar a produção simbólica que governa os processos identitários individuais e coletivos em novas ideias, novas escolhas, novas capacidades de escolhas e, em consequência, novas possibilidades de gestão (SACCO, 2003).

Nesse contexto, as cidades tornam-se um território qualificado de "comum" no qual é tecido um conjunto de relações no intuito de capturar e unir o espaço construído em torno dos fluxos ao espaço dos lugares capazes de potencializar e aproveitar os recursos, abrindo novos caminhos de desenvolvimento local (BAUDOWIN; COLLIN, 2006; CASTELLS, I999; SANTOS, 200I).

Para Silveira (2006), as novas abordagens sobre o desenvolvimento local, baseadas em uma perspectiva sistêmica de articulação socioinstitucional e socioprodutiva, trazem como diferencial significativo a busca de uma intervenção territorializada ao gerarem uma matriz de projetos e ações continuados, por meio da mobilização de diferentes agentes atuantes em torno da transformação do território. Para o autor, essa transformação refere-se a um conjunto de aspectos combinados, envolvendo tanto as formas de produção, circulação e gestão, passando por novos parâmetros de articulação e organização, em que a "comunidade local" emerge como coprotagonista. É nesse contexto que se dá o redescobrimento da dimensão territorial, revelando o elo entre globalização e localização, com a introdução de novas alternativas em torno do desenvolvimento socioterritorial.

Sobre a viabilização do processo de desenvolvimento local por meio do capital socioterritorial e da valorização cultural, Farrell et al. (I999) concebem que esta se constitui na riqueza do território como: recursos naturais (relevo, subsolo, solo, vegetação etc.), equipamentos e infraestruturas, além do patrimônio histórico e arquitetônico; a cultura e a identidade do território (valores, rituais, significados, interesses, formas de reconhecimento comumente partilhados pelos agentes do território); recursos humanos - as pessoas que vivem no território ou que vêm viver nele e os que partem; as características demográficas da população e a sua estruturação social (os ofícios, as competências e o saber-fazer implícito/ explícito); assim como o conhecimento das tecnologias e a capacidade de busca de desenvolvimento; as instituições e administrações locais; as atividades e as pequenas empresas (considerando aqui a sua maior ou menor concentração geográfica e a sua estruturação); os mercados e as relações externas (designadamente a sua integração nos diferentes mercados, redes de troca, de promoção etc.); a imagem e a percepção do território - tanto internas como externas. Assim, as 
chamadas redes sociais atuantes nos territórios são constituídas pelas diferentes formas de organização social e institucional e pelas organizações corporativas e produtivas que atuam nas cidades (DALLABRIDA, 2006).

Essas perspectivas se alinham com a necessidade da integração dos temas da revitalização urbana com a mobilização produtiva da cidade, visando ao desenvolvimento socioterritorial a partir da emergência de novos sujeitos políticos e da constituição do comum: a integração territorial de novas dimensões produtivas e reprodutivas dos territórios das cidades desenhadas pelas redes sociais e pela cooperação social produtiva (COCCO, 2006).

\section{PROCEDIMENTOS METODOLÓGICOS}

A pesquisa foi desenvolvida segundo a abordagem qualitativa, com um estudo inicial do tipo etnográfico, que teve como objetivo mapear os "espaços intermediários”, especificamente os bares e restaurantes e, com base nesse levantamento, delimitar fisicamente o território da cidade para o estudo. A localização dos bares e restaurantes mapeados envolveu espaços contíguos de três diferentes bairros da cidade de Fortaleza. Com isso, o campo empírico foi constituído pelo contexto da cidade, sendo este delimitado pelos limites físicos do território dos três bairros - Aldeota, Meireles e Varjota - no qual estão localizados os bares e restaurantes sob estudo, envolvendo os espaços de convivência e trabalho dos sujeitos e as práticas dos estabelecimentos.

Foi ainda constatado que cada bairro envolvido apresentava diferentes origens e histórias no contexto da cidade. Dessa forma, realizou-se uma pesquisa documental na Biblioteca Pública de Fortaleza, a fim de levantar dados históricos sobre o início da ocupação e formação residencial e comercial dos bairros envolvidos. Segundo Pitt (I972 apud CAVEDON, 2003), o estudo do contexto histórico possibilita a compreensão da estabilidade e da mudança sociocultural, prevenindo possíveis erros de interpretação do presente. No decorrer da pesquisa, um conjunto de técnicas foi utilizado:

- A "etnografia de rua" (ECKERT; ROCHA, 2003) está fundamentada na antropologia urbana (VELHO, I999), que tem por objetivo compreender as especificidades da vida urbana e de que modo os fenômenos socioculturais são produzidos, reproduzidos e vivenciados na vida cotidiana. Na etnografia de rua, o pesquisador percorre os lugares, realiza caminhada, observa o espaço e suas configurações, e interage com os sujeitos que participam da vida social e de trabalho nos lugares envolvidos, com o objetivo de realizar um mapeamento e uma cartografia do território, observando-o de acordo com 
a totalidade de seus trajetos e percursos, analisando os diferentes fluxos de pessoas, moradores, visitantes, trabalhadores e formas de apropriações dos lugares (ECKERT; ROCHA, 2003). Esse procedimento foi complementado pelas técnicas da observação participante e da compilação de notas no "diário de campo" (MALINOWSKI, I975), em diferentes momentos da vida e trabalho dos bares e restaurantes localizados nos bairros percorridos durante $o$ estudo.

- Realizou-se entrevista temática e não estruturada com os proprietários dos bares e restaurantes selecionados para essa etapa da pesquisa. Os temas articulados no roteiro da entrevista refletiam os objetivos desta pesquisa, com o intuito de descrever os significados culturais atribuídos aos espaços intermediários, envolvendo a emergência de bares e restaurantes em três bairros contíguos - Varjota, Meireles, Aldeota - de Fortaleza, discutindo os reflexos da sociabilidade produtiva e de lazer em termos de desenvolvimento socioterritorial da cidade.

Foram entrevistados cinco profissionais que atuam no segmento de bares e restaurantes de diferentes especialidades gastronômicas localizados nos três diferentes bairros. Os sujeitos e estabelecimentos foram selecionados por conveniência, por meio da acessibilidade encontrada durante a fase da pesquisa etnográfica de rua.

Na análise das informações coletadas, utilizou-se a técnica da análise temática que se insere no conjunto das técnicas da análise de conteúdo (BARDIN, 2004), cujo objetivo é evidenciar os itens de significação por meio da descrição do corpus que foi construído, tendo por base as unidades de codificação recortadas do conteúdo das entrevistas, do diário de campo e dos documentos, sendo estas orientadas pelos objetivos desse estudo.

Para isso, foram percorridas as diferentes fases de análise: $\mathrm{I}$. transcrição, constituição do corpus e pré-análise - considerando, segundo Cavedon (2003), que, na coleta de dados dos estudos de natureza etnográfica, ocorre um distanciamento físico e temporal entre a experiência tal como vivenciada pelo pesquisador e a elaboração do texto, procurou-se diminuir essa defasagem mantendo a transcrição do material da forma como se encontrava nas anotações do diário de campo -, 2. leitura flutuante e exploração do material com o estabelecimento de categorias temáticas, 3. tratamento dos dados por meio da descrição e interpretação, e 4. confronto e discussão dos resultados obtidos com a teoria articulada.

Conforme explica Cavedon (2003), o texto etnográfico coloca em evidência um diálogo que se estabelece entre o pesquisador, os pesquisados e a teoria e/ou os primeiros pesquisadores que se ocuparam do tema. Na presente pesquisa, esse diálogo foi organizado à luz de categorias e informações contextuais históricas e 
socioculturais variadas, fazendo emergir a interpretação como elemento intrínseco ao processo de pesquisa. Dessa forma, iniciando com as categorias teóricas, esse processo levou, em um segundo momento, à redefinição das categorias analíticas em torno dos seguintes blocos temáticos, a saber: I. a cidade e a sua história, seus espaços e a sua cultura; 2. a "experiência de rua" e os espaços intermediários dos bares e restaurantes. Por fim, a título de considerações finais, são articulados os temas da gestão e do desenvolvimento socioterritorial da cidade.

\section{CONTEXTUALIZANDO A CULTURA, OS ESPAÇOS INTERMEDIÁRIOS E O DESENVOLVIMENTO SOCIOTERRITORIAL DA CIDADE DE FORTALEZA}

Buscando ressonâncias na literatura articulada na primeira fase deste artigo, expõe-se a seguir a discussão final baseada nas categorias empírico-analíticas definidas durante o processo interpretativo do estudo.

\subsection{A CIDADE E A SUA HISTÓRIA, SEUS ESPAÇOS E SUA CULTURA}

A colonização do Estado do Ceará demora em relação às demais partes do território do Nordeste brasileiro. Tem início de fato, já no final do século XVIII, com a concessão de datas de sesmarias. Em razão da administração do território, começam então a nascer as primeiras aglomerações em torno dos fortes que são construídos com o objetivo de defesa do litoral e implantam-se pontos de apoio para combater as invasões estrangeiras. O forte Schoonemborch (I649-1654), na foz do Rio Pajeú, dá origem à cidade de Fortaleza. Em i654, os holandeses se retiram, e os portugueses retomam o forte, rebatizando-o de Forte Nossa Senhora de Assunção.

A evolução urbana de Fortaleza foi lenta na primeira metade do século XIX e com baixo crescimento demográfico. A população que era de I2.I95 habitantes em I8I3 passa a I6.557 em I837 e chega ao final do século com 50 mil habitantes. Na configuração urbano-regional da primeira metade do século XIX, Fortaleza, por causa da cultura do algodão, já ascende à hierarquia de vila para cidade. Na segunda metade do século XIX, graças, de um lado, à condição de capital sob a centralização político-administrativa do império, e, de outro, ao algodão, do qual se torna o porto exportador, Fortaleza ganha a primazia de província. 
Segundo Harvey (I992), no decorrer de sua evolução, as sociedades apresentam a necessidade de pesquisar a memória e de comunicar valores e significados estabilizados e interpretados nos monumentos arquitetônicos, incorporando e preservando um sentido de memória coletiva. Constatou-se, no decorrer da análise documental, que, ao longo da segunda metade do século XIX, a cidade de Fortaleza expandiu-se e beneficiou-se da construção de praças, monumentos e edifícios públicos. Os serviços urbanos, os transportes e as comunicações foram acrescidos com a pavimentação de ruas, a iluminação pública a gás carbônico, a canalização de água, a construção da estrada de ferro e a implantação do serviço de bonde de tração animal e do telégrafo (PONTE, 200I).

$\mathrm{O}$ arquiteto Adolfo Herbster apresenta um plano urbanístico em I875, no qual recomenda a construção de três bulevares para delinear o centro urbano, inspirando-se nas reformas levadas a efeito em Paris pelo barão Haussmann. Nessa belle époque de Fortaleza, a vida cultural se dinamiza como indica a criação de entidades científicas, literárias e educacionais, como a Academia Francesa e a Padaria Espiritual, fundadas, respectivamente, em I872 e I892 (GONDIM, 2007).

Conforme DaMatta (I997), na cidade há, contudo, locais liminares, transitórios, margens sociais problemáticas onde tudo o que está relacionado ao paradoxo ou à contradição desenha espaços singulares. Nesse sentido, o outro lado da belle époque era o quadro de pobreza e degradação, margens sociais constituídas pela população que acorria em massa para a capital a cada período de estiagem. Com a seca de I932, a cidade incorpora amplos espaços adjacentes, segregados, de ordenamento irregular, com o surgimento das primeiras favelas na malha urbana tecendo diferentes vínculos identitários, mas fragmentados e isolados (CHANLAT, I993; HARVEY, I992).

A população recém-chegada à capital vai produzindo bairros dominados por habitações precárias e ruelas sem infraestrutura. A concentração de um grande número de pessoas sem recursos e sem condições adequadas de saneamento acarretava toda sorte de problemas sociais e econômicos, levando o governo a impor restrições espaciais à circulação dos "flagelados" (SILVA, I992). É provável que o confinamento espacial, espontâneo ou forçado, e a ausência de uma gestão socioterritorial que possibilitasse a convivência das diferenças por meio dos movimentos de passagens nesses interstícios tenham dificultado a ação criativa do homem nesses "espaços singulares" e, sobretudo, a sua integração no contexto da cidade, favorecendo a formação das primeiras favelas de Fortaleza, no início da década de I930, entre estas: Pirambu, Cercado do Zé Padre, Mucuripe e Lagamar. Posteriormente, surgiram Morro do Ouro (I940), Varjota (I945), Meireles e Papoquinho (I950) (SILVA, I992; CERTEAU, I994; BHABHA, I998). 
Do final do século XIX até a primeira metade do XX, Fortaleza recebe um fluxo constante de imigrantes com um perfil jovem, entre I8 e 30 anos, e em sua maioria homens. Os portugueses foram os que mais migraram para o Ceará, atuando em Fortaleza, principalmente no comércio e na indústria de gêneros alimentícios e no mercado imobiliário. O segundo maior grupo de migrantes foi formado pelos sírio-libaneses, destacando-se inicialmente como mascates e comerciantes, passando a atuar também no mercado imobiliário e hoteleiro. Esses trechos extraídos dos documentos possibilitam a compreensão desse contexto histórico ao revelarem os processos de mobilidade e de circulação de pessoas, migrantes que mudam de lugares; da integração e ou segregação e das influências desses grupos minoritários, em termos de estabilidade e mudanças sociais e culturais (SANTOS, 2006).

Com base na observação de Thompson (i990) de que os fenômenos culturais se inserem em processos sócio-históricos e contextos espaçotemporais estruturados, moldando a maneira como as formas simbólicas são entendidas e valorizadas, hoje se percebe que, na articulação entre essas diferentes culturas com aquelas nativas, nesses "entrelugares", teceram-se laços híbridos, estabelecendo alteridades coexistentes na elaboração de estratégias de subjetivação singular e coletiva. Essas estratégias deram início a novos signos de identidade, revelando diferentes códigos culturais e moldando espaços inovadores - tanto de contestação como de colaboração -, sobretudo no âmbito das atividades econômicas - comercial e imobiliário - que caracterizam, ainda hoje, a cidade de Fortaleza (GHADIRI; DAVEL, 2006; ARRUDA, I998; BHABHA, I998, SANTOS, 2006).

No início da década de I990, a capital do Ceará concentrava a maior parte da população e das atividades de sua região metropolitana. Ao longo dessa década e com a ação do capital imobiliário na estruturação urbana de Fortaleza, consolidaram-se as tendências de ocupação e expansão do espaço urbano, delineadas nas décadas anteriores. De modo geral, observou-se a estagnação dos bairros mais antigos, como Antônio Bezerra, Benfica, Joaquim Távora e Jacarecanga (BERNAL, 2004).

No centro da cidade, acentuaram-se o esvaziamento da função habitacional e a transformação do comércio e serviços que permaneceram na região, com o predomínio de estabelecimentos voltados para uma clientela de baixo poder aquisitivo. Novos centros comerciais e de serviços constituíram-se em bairros como Montese, Parangaba e Messejana, que atendem à classe média baixa, e na Aldeota e Água Fria, onde predomina a clientela de renda alta (BERNAL, 2004; GONDIM, 2007).

No litoral leste, bairros de ocupação mais recente - Varjota, Papicu e Cocó - foram integrados à Aldeota, verificando-se neles uma tendência à verticaliza- 
ção e ao adensamento. As amplas avenidas Santos Dumont e Dom Luiz, que atravessam esses bairros, transformaram-se em corredores de comércio, serviços e turismo, atraindo grandes equipamentos, conformando "lugares" e "não lugares" coexistentes e misturados, e caracterizando a emergência de "espaços intermediários" - como altos edifícios de escritórios e residenciais, grandes shopping centers, lojas aglomeradas em pequenos centros comerciais, parques e uma profusão de bares e restaurantes (BERNAL, 2004; AUGÉ, 2004; MAGNANI, I993).

\subsection{A "EXPERIÊNCIA DE RUA" E OS ESPAÇOS INTERMEDIÁRIOS DOS BARES E RESTAURANTES}

Os três bairros contíguos - Meireles, Varjota e Aldeota - estão entre os mais cobiçados para habitação e negócios, e entre os mais concorridos para quem aprecia a vida noturna na cidade de Fortaleza. Localizados em "espaços nobres" da cidade, fronteirando o mar, tornaram-se bairros entre as décadas de I940 e I960, com a gradual mobilidade para o leste, provocada pelo setor imobiliário, dos antigos bairros de Jacarecanga, Benfica e do centro da cidade de Fortaleza (BERNAL, 2004).

Considerando que a apropriação do espaço traduz a maneira como ele é ocupado, seja por objetos, atividades, indivíduos ou grupos, e que, segundo o pressuposto de Magnani (I984), a cidade pode ser apreciada sob o ponto de vista daqueles que nela vivem e que dela se apropriam, historicamente esses bairros se originaram do deslocamento das famílias de empresários que habitavam os elegantes sobrados do bairro industrial de Jacarecanga, dos proprietários de terra que moravam nos logradouros do Benfica, da região do centro onde se localizavam os comerciantes.

Nesse processo de mobilidade e expansão territorial, ocorreu ainda a dilatação, provocada pela imigração proveniente do interior do Estado, das vilas de pescadores e estivadores do Porto do Mucuripe, localizadas nos limites dos bairros de Meireles e Varjota, que viviam em regime de compartilhar o peixe, realizando "banquetes" entre famílias, muitas vezes e ainda hoje com as mesas arranjadas nas calçadas, improvisando restaurantes entre as pequenas casas dos bairros de Mucuripe e Varjota.

Esses processos de mobilidade, transição e transformação urbana baseiamse nas considerações de Chanlat (I993), Harvey (1992) e Santos (2006) de que o espaço se fixa e enraíza em um mundo urbano fragmentado, mas que está sempre em fluxo, transitório, intercambiável em suas fronteiras e coexistente em suas diferenças, construindo e reconstruindo identidades pessoais e sociais, ao refletir a relação que o homem mantém com o ambiente e com os outros. 
Hoje, esses espaços urbanos emersos na zona leste da cidade caracterizam novos espaços e territorialidades com boas condições de solo e infraestrutura, com concentrações da população de renda baixa, média e alta que habita os mesmos bairros, nos altos e luxuosos edifícios residenciais e/ou nas pequenas e descoloridas casas pertencentes à antiga populacão nativa remanescente dos pescadores e estivadores de Mucuripe. Em volta e intercalando as residências desses bairros contíguos - Meireles, Varjorta e Aldeota -, concentra-se um grande número de equipamentos, espaços e arranjos intermediários que se aglomeram e se renovam, caracterizando a "moderna" transitoriedade da cidade de Fortaleza (MAGNANI, I993).

De forma que passados mais de quatro décadas, os bairros pesquisados conservam resquícios dessa população nativa que habita os mesmos lugares, mas recriados por meio de novos fluxos com a emergência de arranjos e "espaços intermediários", sobretudo uma exuberância de bares e restaurantes, unindo "lugares" e "não lugares", e significando os "entrelugares" e adjacências das ruas: Frederico Borges, Tavares Coutinho, Frei Mansueto e Delmiro Gouveia, no bairro Varjota; das avenidas Beira-Mar e Dom Luis e das ruas República do Líbano, Prof. Dias da Rocha, Ana Bilhar, Silva Jathay e Canuto de Aguiar, entrecruzando e unindo os bairro de Aldeota e Meireles (MAGNANI, I993; AUGÉ, 2004; BHABHA, I998).

Durante a experiência da etnografia de rua, realizaram-se longas e repetidas caminhadas nas calçadas de onze ruas, ruelas e avenidas que se cruzam entre os três bairros contíguos, com o propósito de observar o movimento e participar da vida e do trabalho nos arranjos e espaços intermediários ali encontrados: lojas comerciais, oficinas mecânica, salão de beleza, bancos, carpintarias, tapiocarias e tapioqueiras, bancas de revistas e jornais, consultórios médicos e odontológicos, supermercados, casas e prédios residenciais, lanchonetes e, sobretudo, bares e restaurantes. Foram visitados 26 estabelecimentos do total do grande número de bares e restaurantes localizados entre as II ruas e avenidas dos três bairros, sobretudo os 15 bares e restaurantes que se aglomeram entre os números 59 e 350 da Rua Frederico Borges, entrecruzando as esquinas das ruas Delmiro Gouveia, Ana Bilhar e Tavares Coutinho.

Esses bares e restaurantes, ruas e bairros - "espaços intermediários" - percorridos e observados durante a etnografia de rua se caracterizam como "lugares" de experiências vividas, mas produzem identidades "em andamento", o que possibilita a comunicação e negociação que caracterizam os "entrelugares", unindose aos "não lugares", pois são direcionados para os seus usos e fins de sociabilidade produtiva e de lazer, modelando novas identidades baseadas em hibridismos culturais, emersos nesse processo de transformação histórica espaçotemporal da cidade de Fortaleza (MAGNANI, I993; AUGÉ, 2004; BHABHA, I998). 
Nesse contexto urbano, ampliado pela mobilidade de migrantes, pelos fluxos provenientes de suas amplas avenidas entrecortadas com seus becos sinuosos e ruas estreitas, os três bairros em questão atraem antigos e novos moradores, turistas, investidores, pessoas de todos os cantos da cidade e de outras cidades e países, que ali se instalam ou vêm em busca de negócios, diversão e lazer nas várias opções de bares e restaurantes que ali se localizam e se atualizam por meio de novos investimentos com capital local e estrangeiro (SANTOS, 2006).

Apesar de a rotatividade dos estabelecimentos ser considerada mediana pelos especialistas entrevistados do setor gastronômico de Fortaleza, nesses espaços contíguos e intermediários se encontram bares e restaurantes que operam há décadas. Alguns amplos e luxuosos foram construídos a partir da adaptação das antigas e luxuosas residências localizadas nas avenidas Dom Luís, Santos Dumont e Beira Mar. Há ainda outros, pequenos e pitorescos, com as suas mesas posicionadas nas calçadas das ruelas de Varjota, defronte as pequenas casas ainda habitadas pelos antigos moradores e ou reformadas e adaptadas pelos novos proprietários que ali se instalaram.

Quando se percorrem esses bairros, distintos significados espaçotemporais se entrecruzaram, transformando e criando originais injunções do cotidiano. Dependendo do horário do dia, da tardinha, da noite e ou da madrugada - no almoço, happy hour e/ou jantar -, o dinamismo e a quietude nesses bairros se alteram e se metamorfoseiam, expressando tempos simultâneos e espaços diferenciados, caracterizando lugares unidos por fluxos de não lugares de diferentes formas, cores, luzes e sombras, movimentos e fins: desde a presença das vans e caminhões entregadores de mercadorias e bebidas estacionados nas calçadas nas primeiras horas da manhã; passando pelo intenso trânsito de pessoas e ruidoso tráfego de veículos nas ruas, avenidas e ruelas durante os tempos de trabalho; ao som dos diferentes estilos musicais provenientes das bandas que tocam seus instrumentos nos bares repletos de mesas ocupadas pelos sociáveis e alegres frequentadores nos tempos do pós-trabalho; lugares e não lugares de tempos mutantes, concomitantes e espaços intermediários intersticiais onde pessoas e grupos de pessoas, casais, famílias se encontram e tecem a trama do cotidiano, do trabalho, do desfrute do lazer, da troca de informações e de serviços, dos inevitáveis conflitos e da participação em atividades vicinais (MAGNANI, I993).

Nos fins de semana, as atividades do ócio, do descanso e do trabalho se confundem, confundindo os tempos e espaços; e, nesses interstícios, a experiência por ruas, calçadas e bairros depara inesperadamente com as "festas nos pedaços" da cidade, permeadas pelo murmúrio das conversações e dos risos ao liberarem-se das normas restritivas, configurando-se "uma forma primordial, 
marcante, da civilização humana" (BAKHTIN, I993). Esse clima de festividade e celebração perdura durante todo o dia do sábado até altas horas da madrugada, em que se perde a noção do tempo transitando entre os bares e restaurantes, possibilitando os encontros e desencontros, à procura de saborear os petiscos, as comidas, os doces, os cafés e participar dos prazeres de Baco nas rodadas de chope, da cerveja, da caipirinha e dos inúmeros outros coquetéis alcoólicos e não alcoólicos (MAGNANI, I984).

Durante as caminhadas nas ruas que ligam os bairros percorridos, diferentes rituais foram observados, revelando, segundo Segalen (2000), suas plasticidades ao se acomodarem às mudanças temporais e espaços sociais, expressando diferentes significados e contextos culturais (THOMPSON, I990). Os frequentadores desses bairros são os mais diversos: antigos moradores que, no finalzinho das tardes, ainda mantêm o ritual de colocar a cadeira nas calçadas de suas casas para prosar com os vizinhos; novos moradores separados e incomunicáveis nos altos e luxuosos edifícios; turistas e trabalhadores, investidores, empresários e políticos, que saem do seu cotidiano de casa e trabalho para desfrutar do mundo da culinária e do ritual do encontro para compartilhar a alimentação que vai da simples e popular "panelada", a típica e tradicional "peixada", às mais sofisticadas iguarias orientais - chinesas e japonesas. Há ainda a gastronomia internacional - italiana, francesa, portuguesa -, como: filé de sirigado à Capistrano, peixe do Patativa, carne de sol nordestina com purê de macaxeira, rodízios de churrascos, filé de tilápia crocante do sertão, camarão no abacaxi, festival de sushi, camarão à moda dragão do mar, bacalhau à Gomes de Sá, camarão ao molho de coco com legumes, camarão na moranga, galinha de capoeira à moda da serra, capote à sertanejo, lombo de porco à Jandaíra, filé de peixe de congrio ao Mucuripe, lula na cerveja, paleta de cabrito, espaguete ao molho de frutos do mar; os aperitivos de caranguejos e os doces à base de manga flambada com sorvete de rapadura e banana flambada com sorvete de manjericão.

Percebeu-se, portanto, uma experiência social e produtiva urbana, baseada em diferentes processos históricos, culturais e de identificação enraizados em memórias e tempos passados, revelando uma apropriação simbólica das representações do lugar assimiladas e integradas coletivamente, significando os "entrelugares", mas transitórias, "em andamento", conformando e atualizando os "espaços intermediários" que caracterizam "lugares" e "não lugares" coexistentes e que nunca se realizam completamente (CARRIERI; PEREIRA, 2003; CARRIERI; PAULA; DAVEL, 2008; HALL, 2005; AUGÉ, 2004; BHABHA, I998; MAGNANI, I993). 


\section{CONSIDERAÇÕES FINAIS: A CIDADE, A SUA GESTÃÓ E O DESENVOLVIMENTO SOCIOTERRITORIAL}

Nas cidades contemporâneas, as mudanças socioespaciais se operam numa temporalidade acelerada, acarretando um descompasso entre o crescimento demográfico, as práticas espaciais e a implantação de políticas públicas voltadas para suprir as necessidades desse movimento de desterritorialização dos fluxos no sentido da reterritorialização, por meio do estímulo da criação, da reinvenção do cotidiano dos lugares, em uma base de comunicação entre os diferentes códigos culturais e de cooperação entre os interesses daqueles que vivem, habitam e atuam nos espaços urbanos.

A sociedade contemporânea atribui ênfase ao papel das assim chamadas "cidades mundiais" ao atrair o capital móvel, estimulando as elites dirigentes locais a implementar estratégias de melhorias das competências das pessoas, do fornecimento de infraestrutura e de política fiscal, com o objetivo de atrair o desenvolvimento para o seu espaço particular: a "produção ativa dos lugares se torna um trunfo na competição espacial entre localidades, cidades, regiões e nações" (HARVEY, I992, p. 266).

Seguindo essa tendência mundial, ao longo da década de I990 a imagem de Fortaleza transformou-se radicalmente: antes vista como a capital da seca, passou a ser apresentada como uma espécie de "paraíso tropical". A atratividade de Fortaleza como destino turístico evidencia-se no incremento de $30 \%$ na frequência de turistas nos primeiros anos da década de I990. Em I997, a cidade foi o destino mais procurado pelos turistas brasileiros (BENEVIDES, 2002).

Um dos fatores essenciais da construção simbólica e material da "nova" cidade refere-se às intervenções e revitalizações urbanísticas aliadas à mobilização social e produtiva da cidade, realizadas a partir do início da década de I990 pela prefeitura e pelos assim chamados "governos das mudanças", no contexto da disputa pela hegemonia política da capital: a rede de esgoto sanitário, o novo aeroporto internacional, o transporte metroviário ainda em construção, a abertura de novas ruas, parques e avenidas. E, ainda, um conjunto de equipamentos culturais como o Centro Dragão do Mar de Arte e Cultura, que envolveu a restauração de antigos armazéns e casarões históricos, paralelamente à construção de modernos museus, salas de exposição, cinemas, teatros, auditórios e bibliotecas, lojas de artesanato e livrarias, planetário, quadras de esportes, praças e passarelas repletas de cafés, bares e restaurantes - revitalizando e unindo espaços ao entrelaçar o tecido urbano com o social e os objetivos econômicos com os simbólicos (GONDIM, 2007; REIS, 2007). Equipamentos definidores de fronteiras, de passagens, intersticiais, liminares e singulares; "espaços intermediários" unindo 
"lugares" e "não lugares", suportes concretos de "experiências de rua" de sociabilidade produtiva, cultural e de lazer (MAGNANI, I993; AUGÉ, 2004; COCCO, 2006; BHABHA, I998).

Apesar de os indicadores socioespaciais estaduais apresentarem Fortaleza como uma cidade privilegiada em comparação às demais do Nordeste brasileiro, sobressai da observação mais atenta e "estranhada" que a cartografia da cidade está construída sob o signo da desigualdade, caracterizando a diversidade na unidade, mas apartada em duas, constituída por um mix de opulência ao leste e de miséria ao oeste (ARAÚJO; CARLEIAL, 2003).

Essas evidências emersas nas observações e caminhadas nas ruas percorridas são corroboradas com base nos indicadores do estudo de Araújo e Carleial (2003), que afirmam que o habitar em Fortaleza mostra a coexistência espacial de ricos e pobres, inclusive em um mesmo bairro. Essa fragmentação do espaço é visível e desvela as heterogeneidades e as homogeneidades culturais dos espaços intraurbanos e intermediários inerentes aos bairros, revelando uma apropriação física e simbólica do espaço urbano de modo desigual.

Para Pitaudi (200I), a existência de "duas cidades em Fortaleza" retoma a história de sua ocupação territorial, respaldada na estreita relação entre as transformações das práticas socioeconômicas e na consequente apropriação do espaço urbano. Essa relação se respalda no paradoxo, segundo Harvey (I992), que quanto maior o incentivo para que os lugares se diferenciem de maneira atrativa ao capital, aos negócios e ao turismo, tanto maior tem sido a fragmentação da insegurança e do desenvolvimento desigual efêmero no interior da "economia de fluxos".

Essas constatações refletem como a gestão de uma cidade faz uso dos seus espaços, desvelam os seus "entrelugares", lugares de passagens, intersticiais, intermediários, liminares, físicos e simbólicos, refletindo a necessidade de pensar e integrar os processos culturais ao desenvolvimento socioterritorial, com base nas relações de identidade, enraizamento, territorialização e desenraizamento, desterritorialização e reterritorialização no contexto da cidade (CARRIERI; PEREIRA, 2003; VASCONCELOS, 2003; BHABHA, I998; REIS, 2007; IPIRANGA et al., 2006; BARBALHO, 2009).

Nesse sentido, destacam-se as observações de Reis (2007) sobre a necessidade de formulação de políticas públicas voltadas para a requalificação urbano-geográfica e elevação da qualidade de vida das cidades, por meio do investimento em cultura como "agente recuperador", entrelaçando o tecido urbano com o social e os objetivos econômicos com os simbólicos.

Nesse processo, a cultura local emerge como um fenômeno social difuso ao aplicar a produção simbólica que governa os processos identitários individuais e coletivos, que caracterizam os "espaços intermediários" em novas ideias, novas 
escolhas e novas capacidades de escolhas, sugerindo novas possibilidades de gestão. A cultura age, portanto, como agente sinérgico, projetando as intervenções urbanísticas com base na identidade da cidade e da comunidade que habita os "lugares" e objetiva os "não lugares" (SACCO, 2003; AUGÉ, 2004).

As várias atividades e iniciativas de base cultural se transformam em uma linguagem, aliando a dimensão racional e emocional, auxiliando os indivíduos a compreender como o crescente envolvimento da dimensão cultural nos modelos de interação econômica e social implicará a potencial transformação das oportunidades profissionais e dos objetivos existenciais a serem perseguidos (SACCO, 2003).

Parafraseando Magnani (I993), Augé (2004) e Certeau (I994), a ideia é aquela de desvelar os "espaços de enunciação", significando os "entrelugares", os caminhos entrecruzados que dão forma a novos "espaços intermediários" que unem os "lugares antropológicos" e "não lugares" em um desenho singular e que, muitas vezes, se sobrepõem ao desenho oficial da cidade, ao construírem pontes capazes de compartilhar os códigos culturais entre os espaços de fluxo e as diferentes formas de lugares: esse é o desafio para os gestores das cidades.

Por fim, releva-se a importância de se abrir uma agenda de pesquisa no campo de estudos organizacionais, direcionada para os estudos do tema "cidade" e a sua gestão, como complexa organização social, articulando abordagens que envolvam as dimensões espaçotemporais em suas nuanças e interfaces econômicas, sociais e culturais.

\section{REFERÊNCIAS}

ALCADIPANI, R.; ALMEIDA, A. O. O feitiço incluiu o feiticeiro: uma análise sobre a implementação de um escritório aberto. In: ENCONTRO ANUAL DA ASSOCIAÇÃO NACIONAL DOS PROGRAMAS DE PÓS-GRADUAÇÃO EM ADMINISTRAÇÃO, 200I, Florianópolis. Anais... Florianópolis: EnAnpad, 200I.

ARAÚJO, A. M. M.; CARLEIAL, A. N. Opulência e miséria nos bairros de Fortaleza. (Ceará/Brasil). Cripta Nova, Barcelona, v. VIII, n. I46, ago. 2003.

ARRUDA, A. (Org.). Representando a alteridade. Petrópolis: Vozes, I998.

AUGÉ, M. Não-lugares: introdução a uma antropologia da supermodernidade. Campinas: Papirus, 2004 .

BAKHTIN, M. A cultura popular na Idade Média e no Renascimento. São Paulo: Hucitec; Brasília: Edunb, I993.

BARBALHO, A. Cultura e cidade. In: MAMEDE, M. A.; GADELHA, R. (Org.). Economia criativa. Uma nova perspectiva. Anais do I Seminário Nacional de Economia Criativa. Anais... Fortaleza, Ceará, nov. 2009.

BARDIN, L. Análise do conteúdo. Lisboa: Edições 70, 2004. 
BHABHA, H. K. O local da cultura. Belo Horizonte: Ed. UFMG, I998.

BARTHES, R. O prazer do texto. São Paulo: Perspectiva, I996.

BAUDOWIN, T; COLLIN, M. O território do comum na mobilização produtiva dos atores da cidade. In: SILVA, G.; COCCO, G. (Org.). Territórios produtivos. Oportunidades e desafios para o desenvolvimento local. Rio de Janeiro: DP\&A; Brasília, DF: Sebrae, 2006.

BENEVIDES, M. G. Liberdade e escravidão: uma visão orwelliana das histórias e das memórias do processo de transformação institucional do Banco do Brasil (I984-2000). Fortaleza: Gráfica LCR, 2002.

BERNAL, C. A metrópole emergente: a ação do capital imobiliário na estruturação urbana de Fortaleza. Fortaleza: Edições UFC, 2004.

BOURDIEU, P. Razões práticas. Sobre a teoria da ação. Campinas: Papirus, I996.

CARRIERI, A. de P.; PEREIRA, D. C. Movimento de desterritorialização e reterritorialização na transformação cultural: um estudo de doze anos em uma empresa do setor de telecomunicações. In: IX COLÓQUIO INTERNACIONAL SOBRE PODER LOCAL, 9., 2003, Salvador. Anais... Salvador, jun. 2003 .

CARRIERI, A. de P.; PAULA, A. P. de; DAVEL, E. Identidade nas organizações: múltipla, fluida, autônoma? O\&S Organização \& Sociedade: publicação da Escola de Administração da Universidade Federal da Bahia - EAUBA, Salvador, v. I5, n. 45, p. I27-I44, abr./jun. 2008, p. I27-I44. Especial Poder Local.

CASTELLS, M. A sociedade em rede. A era da informação, economia, sociedade e cultura. São Paulo: Paz e Terra, I999. v. I.

CAVEDON, N. R. Antropologia para administradores. Porto Alegre: Editora da UFRGS, 2003.

CERTEAU, M. A invenção do cotidiano. Petrópolis: Vozes, I994.

CHANLAT, J. F. O indivíduo na organização. Dimensões esquecidas. São Paulo: Atlas, I993. v. II.

COCCO, G. Mobilizar os territórios produtivos: para além do capital social, a constituição do comum. In: SILVA, G.; COCCO, G. (Org.). Territórios produtivos. Oportunidades e desafios para o desenvolvimento local. Rio de Janeiro: DP\&A; Brasília: Sebrae, 2006.

DALLABRIDA, V. R. A gestão social dos territórios nos processos de desenvolvimento territorial: uma aproximação conceitual. In: COLÓQUIO INTERNACIONAL SOBRE PODER LOCAL, IO., 2006, Salvador. Anais... Salvador, 2006.

DAMATTA, R. O que faz o brasil, Brasil? Rio de Janeiro: Rocco, I99I.

A casa \& a rua. Espaço, cidadania, mulher e morte no Brasil. Rio de Janeiro: Rocco, I997.

ECKERT, C.; ROCHA, A. L. C. da. Etnografia de rua: estudo de antropologia urbana. RUA: revista do Núcleo de Desenvolvimento da Criatividade da Unicamp, Campinas, n. 9, p. IoI-I27, mar. 2003.

FARRELL, G. et al. A competitividade territorial: conceber uma estratégia de desenvolvimento territorial à luz da experiência Leader. Observatório Europeu Leader: inovação em meio rural, n. 6, dez. I999.

FISCHER, T. Gestão contemporânea, cidades estratégicas: aprendendo com fragmentos e configurações do local. In: Gestão contemporânea: cidades estratégicas e organizações locais. Rio de Janeiro: Fundação Getulio Vargas, I996.

FISCHER, T. et al. Teias urbanas, puzzles organizativos: inovações, continuidades e ressonâncias culturais. In: ENCONTRO ANUAL DA ASSOCIAÇÃO NACIONAL DOS PROGRAMAS DE PÓS-GRADUAÇÃO EM ADMINISTRAÇÃO, I996, Rio de Janeiro. Anais... Rio de Janeiro: Anpad, I996. 
FISCHER, T. et al. A cidade como teia organizacional: inovações, continuidades e ressonâncias culturais - Salvador da Bahia, cidade puzzle. In: MOTTA, F. C. P.; CALDAS, M. P. (Org.). Cultura organizacional e cultura brasileira. São Paulo: Atlas, I997.

FORTUNA, C. Cidade, cultura e globalização. Oeiras: Celta, $200 \mathrm{I}$.

GEERTZ, C. A Interpretação das culturas. Rio de Janeiro: LTC, I989.

GHADIRI, D. P.; DAVEL, E. Do sólido ao fluido: contradição organizacional e paradoxo na reconstrução de identidade. RAE-Eletrônica, v. 5, n. I, jan./jun. 2006.

GONDIM, M. P. L. O dragão do mar e a Fortaleza pós-moderna. Cultura, patrimônio e imagem da cidade. São Paulo: Annablume, 2007.

HALBWACHS, M. A memória coletiva. São Paulo: Centauro, 2006.

HALL, S. A identidade cultural na pós-modernidade. Rio de Janeiro: DP\&A, 2005.

HARVEY, D. Condição pós-moderna. Uma pesquisa sobre as origens da mudança cultural. São Paulo: Edições Loyola, I992.

IPIRANGA, A. S. R. et al. Um passeio no espaço e no tempo: o desvelar da identidade da cidade de Fortaleza através da antropologia visual. In: COLÓQUIO INTERNACIONAL SOBRE PODER LOCAL, Io., 2006, Slavador. Anais... Salvador, 2006.

LEITÃO, C. S. Memória do comércio cearense. Rio de Janeiro: Senac, 200I.

MAC-ALLISTER, M. A cidade no campo dos estudos organizacionais. In: COLÓQUIO INTERNACIONAL SOBRE PODER LOCAL, 9. 2003, Salvador. Anais... Salvador, 2003 a.

. Emergência do espaço organizacional para a gestão social. In: COLÓQUIO INTERNACIONAL SOBRE PODER LOCAL, 9. 2003, Salvador. Anais... Salvador, 2003b.

MAGNANI, J. G. C. Festa no pedaço: cultura popular e lazer na cidade. São Paulo: Brasiliense, I984.

Os pedaços da cidade. São Paulo: USP, CNPq, I99I. (Relatório de Pesquisa).

A rua e a evolução da sociabilidade. São Paulo: Brasiliense, I993.

MALINOWSKI, B. Argonautas do Pacífico ocidental. São Paulo: Abril Cultural, I975. (Os pensadores, v. XLII).

MESQUITA, Z. Espaco, território e lugar: estas palavras ciganas... Educacão, Subjetividade \& Poder, Ijuí, v. 5, p. 64-75, jul. I998.

PITAUDI, S. M. A cidade e as formas de comércio. In: CARLOS, A. F. A. (Org.). Novos caminhos da geografia. São Paulo: Contexto, 200I. p. I43-I59.

PONTE, S. R. da. Fortaleza belle époque: reformas urbanas e controle social. Fortaleza: Fundação Demócrito Rocha, 200I.

REIS, A. C. F. Economia da cultura e desenvolvimento sustentável. O caleidoscópio da cultura. São Paulo: Manole, 2007.

SACCO, P. L. Prendere la cultura sul serio? Essere competitivi nell'economia post-industriale. In: OSSERVATORIO IMPRESA E CULTURA (A cura di). Cultura e Competitivita. Per um nuovo agire imprenditoriale. Roma: Rubbettino, 2003.

SANTOS, M. Por uma outra globalização: do pensamento único à consciência universal. Rio de Janeiro: Record, 200I.

A natureza do espaço. São Paulo: Edusp, 2006.

SEGALEN, M. Ritos e rituais. Portugal: Europa-América, 2000. 
SILVA, J. B. da. Os incomodados não se retiram. Fortaleza: Multigraf, I992.

SILVEIRA, C. M. Desenvolvimento local: uma hipótese política. In: SILVA, G.; COCCO, G. (Org.) Territórios produtivos. Oportunidades e desafios para o desenvolvimento local. Rio de Janeiro: DP\&A; Brasília: Sebrae, 2006.

THOMPSON, J. B. Ideologia e cultura moderna. Teoria crítica na era dos meios de comunicação de massa. Petrópolis: Vozes, I990.

VASCONCELOS, P. A. Categorias e conceitos fundamentais na geografia. In: COLÓQUIO INTERNACIONAL SOBRE PODER LOCAL, 9., 2003, Salvador. Anais... Salvador, 2003.

VELHO, G. (Org.). Antropologia urbana. Cultura e sociedade no Brasil e em Portugal. Rio de Janeiro: Jorge Zahar, I999. 